\title{
The formation of copper oxide nanorods in the presence of various surfactant micelles
}

\author{
Nishtar Nishad Fathima ${ }^{\mathrm{a}}$, Anantanarayanan Rajaram ${ }^{\mathrm{b}}$, B. Sreedhar ${ }^{\mathrm{c}}$ and Asit Baran Mandal ${ }^{* a}$ \\ ${ }^{a}$ Chemical Laboratory, Physical and Inorganic Chemistry Division, Central Leather Research Institute, \\ Adyar, Chennai, India. \\ ${ }^{b}$ Biophysics Laboratory, Central Leather Research Institute, Adyar, Chennai, India. \\ ${ }^{c}$ Physical and Inorganic Chemistry Division, Indian Institute of Chemical Technology, Hyderabad, India. \\ abmandal@hotmail.com*; abmandal@clri.res.in
}

\begin{abstract}
Copper oxide nanorods with average diameters and lengths of $c a .8 \mathrm{~nm}$ and $400 \mathrm{~nm}$, respectively, have been prepared by a simple onestep solid-state reaction in the presence of various surfactant micelles. The effect of three different surfactants viz., SDS, CTAB and Triton X-100 and their critical micellar concentration (CMC) on the formation of nanorods has been studied using $X R D, T E M, D S C$ and XPS techniques. It is found that the formation of the nanorods in the presence of SDS micelles is better with higher thermal stability and possessing lower binding energy with regard to $\mathrm{Cu}_{2 p}$ peak.
\end{abstract}

Keywords: nanostructures; $\mathrm{X}$ - ray diffraction topography; Differential scanning calorimetry (DSC), oxides

Introduction

Organized inorganic nanopore networks find potential use in catalysis (Tanev et al., 1994; Burch et al., 1996), separating technology (Barres, 1982) and biomaterials engineering (Ohgushi et al., 1992; Guillemin et al., 1987). One-dimensional (1D) nanoscale materials are currently of great interest due to their unique electronic, optical, and mechanical properties (Jiang et al., 2000; Zhu et al., 2002; Duan et al., 2003). Owing to these reasons, many researchers worldwide have focused their attention to synthesize onedimensional nano materials. The existing methods for synthesizing such nano particles are complex, energy intensive and require high temperatures and long durations (Lin \& Mou, 1996; Liao et al., 2001). Hence, the need arises to develop a simple way to synthesize these materials. Surfactant templates are generally employed in the synthesis of the same. Suspended single-walled carbon nanotubes and many nano materials formation in presence of surfactant and mixed surfactant systems have been reported (Hao et al., 2004; Moore et al., 2003). The effect of sodium dodecylsulfate (SDS) and dodecyltrimethylammonium bromide (DTAB) on morphologies of gold nanoparticles in the presence of poly (amidoamine) dendrimers has been reported recently (Bakshi et al., 2006). A novel and simple one-step solid-state reaction in the presence of a suitable polyethylene glycol viz. PEG-400 has been reported (Wang et al., 2001) recently to synthesize uniform copper oxide nanorods. The formation of a rod shape of copper oxide could be due to the surfactant assemblage, because PEG in water can form a chain structure (Sun et al., 2000). However, to the best of our knowledge, low molecular weight PEG in aqueous solution does not form micelles. Therefore, in this investigation, we have used various surfactants viz. sodium dodecylsulfate (SDS), cetyltrimethyl-ammonium bromide (CTAB) and Triton X-100 as real micelleforming agents for the first time in synthesizing copper oxide nano materials. The reason for using the above surfactants is also to understand the effect of different charges (anionic, cationic and neutral) and concentrations (below CMC and above $\mathrm{CMC}$ ) of the surfactants on the formation of nanorods. In order to address the question of whether the micelles act as catalyst or template for the preparation of the nanorods, we have synthesized the above materials using surfactants below and above their critical micelle concentration (CMCs) with a view to stimulate further studies.

In this paper, copper oxide has been chosen owing to its varied technological applications (Berry et al., 1988; Malandrino et al., 1997a,b). It is the basis for several high- $T_{c}$ superconductors. The $\mathrm{CuO}$ is a $p$-type semiconductor with a band gap of $1.2 \mathrm{eV}$ commonly studied for its photoconductive properties and photothermal applications (Rakhshani, 1986, Wu et al., 1987). $\mathrm{Cu}_{2} \mathrm{O}$ and related materials are the subject of much current interest for use in high performance batteries (Poizot et al., 2000).

\section{Materials and methods}

\section{Materials}

$\mathrm{CuCl}_{2} \cdot 2 \mathrm{H}_{2} \mathrm{O}$ and $\mathrm{NaOH}$ of analytical grade purity were purchased from Ranbaxy Chemicals, India. Regarding grade, purity and characteristics of the surfactants, we have described in details in our earlier publications (Mandal et al., 1980; Mandal, 1993; Mandal \& Nair 1991; James et al., 2005).

Methods

$3.020 \mathrm{~g}$ of $\mathrm{CuCl}_{2} \cdot 2 \mathrm{H}_{2} \mathrm{O}$ and $2 \mathrm{~g}$ of $\mathrm{NaOH}$ were ground for 5 min each before mixing together; $5 \mathrm{~g}$ of SDS (a) / CTAB (b) / Triton X-100 (c), was then added to the mixture. After 30 min grinding, the mixture was washed in an ultrasonic bath three 
times with distilled water. Finally, it was air dried at $65^{\circ} \mathrm{C}$ for $2 \mathrm{~h}$. In another set of experiments, the above procedure was followed using very small amount of surfactants so that the concentrations of the surfactants are below their CMCs. X-ray powder diffraction was carried out on a Shimadzu XD-D1 X-ray diffractometer with $\mathrm{Cu}-\mathrm{K} \alpha$ radiation

Fig. 1. XRD patterns of as-prepared copper oxide nanorod samples prepared using (a) SDS, (b) CTAB and (c) Triton $X-100$ micelles.

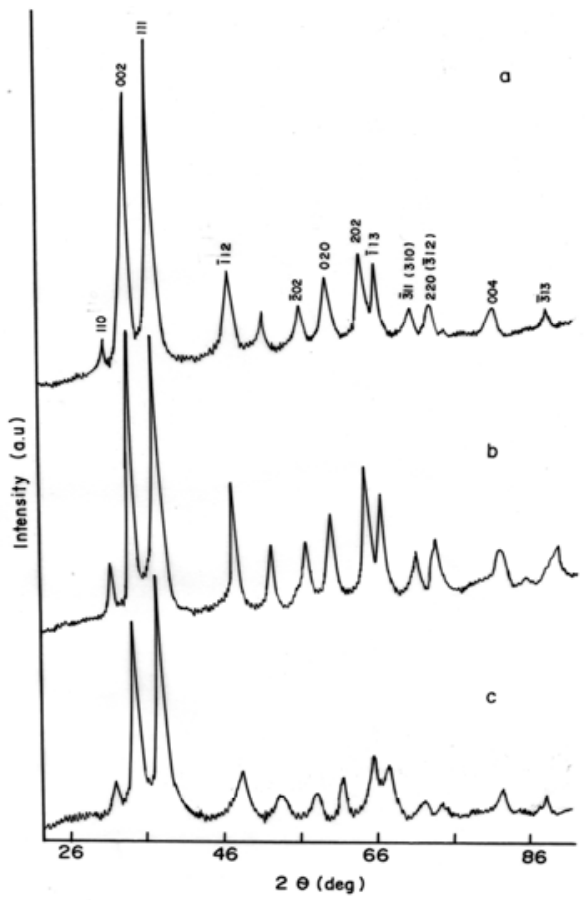

$(\lambda=1.5405 \AA)$. Transmission electron microscopy (TEM) micrographs were taken using a JEOL EM1200 Ex II transmission electron microscope, with an accelerating voltage of $80 \mathrm{kV}$. The samples were fused in a differential scanning calorimetric cell of a Mettler Toledo Star system differential scanning calorimeter (DSC). The temperature was calibrated effectively using indium as standard. The heating rate was $10^{\circ} \mathrm{C} / \mathrm{min}$ and temperature was varied from 30 to $600^{\circ} \mathrm{C}$ under $\mathrm{N}_{2}$ atmosphere. The XPS measurements were conducted with a Kratos XPS Axis 165 spectrometer equipped with hemispherical energy analyzer. The non-monochromatized AlK $\alpha$ X-ray source was operated at pass energy of $160 \mathrm{eV}$ with an increment of $0.1 \mathrm{eV}$. The binding energy of $\mathrm{C} 1 \mathrm{~s}$ core level (binding energy $=284.6 \mathrm{eV}$ ) of adventitious hydrocarbon was used as a standard. The XPS spectra were fitted using a non-linear least square method with the convolution of Lorentzian and Gaussian functions after a polynomial background was subtracted from the raw spectra.

Results and Discussion

The obtained powders were characterized by X-ray powder diffraction (XRD) (Fig. 1 a, b, c). Powder XRD peaks of the copper oxide are consistent with the data of the JCPDS file (JCPDS International center for Diffraction Data, 1991). The peaks at $2 \theta$ values of $32.53,35.41,38.73,45.20$, $48.86,53.53,58.63,60.27,67.98,74.94$ and $81.27^{0}$ correspond to the crystal planes of 110 , 002, 111, $\overline{1} 12, \overline{2}$ 02, 020, 202, $\overline{1} 13,220(\overline{3} 12)$, $004, \overline{3} 13$ of crystalline copper oxide, respectively, which are in good agreement with the recent observations (Wang et al., 2001). It could be seen

Fig. 2. TEM images of as-prepared copper oxide nanorod samples prepared using a) SDS, (b) CTAB and (c) Triton $X-100$ micelles.

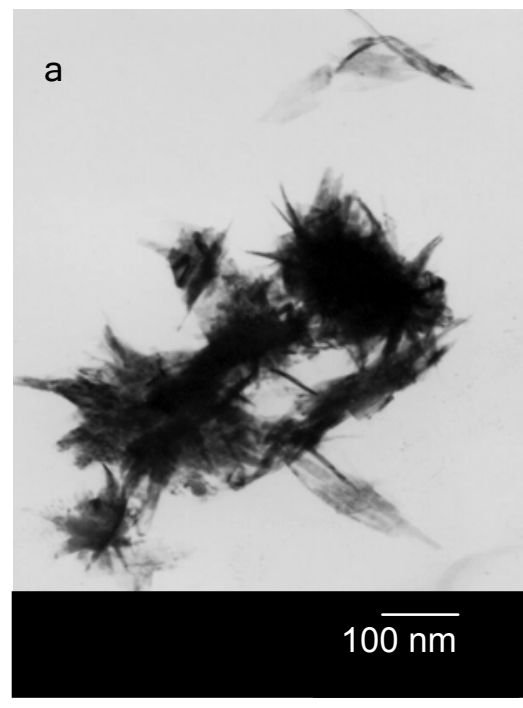

iSee (C) category: Research article Indian Society for Education and Environment


"CuO nanorods" 
that the XRD patterns for all the three samples are same except for varying intensity and broadness of some of the peaks. The nano particles so obtained have rod like structure according to transmission electron microscopy studies with diameter of ca. 8 $\mathrm{nm}$ and length of ca. $400 \mathrm{~nm}$ (Fig. $2 \mathrm{a}, \mathrm{b}, \mathrm{c}$ ). The TEM picture for the copper oxide nanorods in the presence of SDS micelles is sharp compared to the other two (i.e., in CTAB and Triton-X-100 micelles). The XRD pattern correlates with respect to the fact that in nanoparticles since there are not many atomic layers, the pattern can be somewhat diffuse (Fig. 1a), which is however, less than that for a thicker crystal where it can be very sharp (Fig. $1 \mathrm{~b})$. Crystals have not formed well with Triton X100. The TEM and XRD pattern show less crystallinity and presence of more amorphous

Fig. 3. DSC thermograms of as-prepared copper oxide nanorod samples prepared using (a) SDS, (b) CTAB and

(c) Triton X-100 micelles.


iSee $\odot$ category: Research article Indian Society for Education and Environment
Table 1. Exothermic peaks of as-prepared samples in the presence of three different surfactants with concentration below and above CMC from DSC studies

\begin{tabular}{|l|l|l|}
\hline Surfactant & $\begin{array}{l}\text { Peak } \\
\text { temperature }\left({ }^{\circ} \mathrm{C}\right) \\
\text { Above CMC }\end{array}$ & $\begin{array}{l}\text { Peak } \\
\text { temperature }\left({ }^{\circ} \mathrm{C}\right) \\
\text { Below CMC }\end{array}$ \\
\hline SDS & 278 & 275 \\
CTAB & 259 & 258 \\
$\begin{array}{l}\text { Triton } \mathrm{X}- \\
100\end{array}$ & 234 & 230 \\
\hline
\end{tabular}

compound (Hwang et al., 2001). The low molecular weight anionic surfactant viz. SDS gives better nanoparticles compared to CTAB and Triton X-100. Our results are in good agreement with the recent results obtained by Bakshi et al. (2006).

We have chosen Triton $\mathrm{X}-100$ because the hydrophilic head group of Triton X-100 containing 9 oxyethylene units (Mandal et al., 1980), which is equivalent to PEG-400. Controlled aging of $\mathrm{TiO}_{2}$ nanoparticles blended with diblock copolymers and processed into dip-coated thin films led to ordered nanostructures with cubic and hexagonal symmetries that can be transformed into mesoporous $\mathrm{TiO}_{2}$ by using some steps has recently been reported (Hwang et al., 2001). Monodispersed nanocrystalline $\mathrm{CeO}_{2}$ powders of size ca $2 \mathrm{~nm}$ displaying quantum size effects have recently been prepared (Liao et al., 2001) by microwave irradiation in aqueous solution containing $\left(\mathrm{NH}_{4}\right)_{2} \mathrm{Ce}\left(\mathrm{NO}_{3}\right)_{6}, \mathrm{PEG}$ and $\mathrm{NaAc}$.

In order to better understand the components and thermal behavior of the as-synthesized product, we carried out DSC of the copper oxide nanorods. The DSC thermograms of the assynthesized nanorods in the presence of SDS, CTAB and Triton X-100 show an exothermic peak centered at 278,259 and $234^{\circ} \mathrm{C}$, respectively (Fig. 3 ). It is interesting to note that there is another peak obtained at $281^{\circ} \mathrm{C}$ for the nanorod sample made in the presence of Triton X-100 (cf. Fig.3c). This may be due to the polydispersive nature of Triton X-100 surfactant micelles. It is seen that nanorods with SDS have more thermal stability compared to those based on other surfactants. The

Table 2. Binding energies peaks of $\mathrm{Cu}_{2 p}$ for the asprepared samples in the presence of three different surfactants with concentration below and above

$$
\text { CMC }
$$

\begin{tabular}{|l|l|l|}
\hline Surfactant & $\begin{array}{c}\text { Binding energy } \\
\text { (eV) Above } \\
\text { CMC }\end{array}$ & $\begin{array}{c}\text { Binding energy } \\
\text { (eV) Below } \\
\text { CMC }\end{array}$ \\
\hline SDS & 933.38 & 934.08 \\
CTAB & 933.64 & 934.26 \\
Triton X-100 & 933.55 & 933.14 \\
\hline
\end{tabular}

"CuO nanorods"

by Fathima et al. Indian J.Sci.Technol. 
Fig. 4. Wide scan X-ray photoelectron spectra of the as-prepared CuO nanorod samples using (a) SDS, (b) CTAB and (c) Triton X-100 micelles.


nanorods samples, the binding energies for below CMC concentrations are 0.70 and $0.62 \mathrm{eV}$, respectively and are higher than that for above CMC samples, whereas for Triton X-100 based nanorods, a reverse trend is observed (cf. Table 2). It is well established that $\mathrm{CuO}$ and $\mathrm{Cu}_{2} \mathrm{O}$ decompose at 1026 and $1235^{\circ} \mathrm{C}$, respectively. However, in the present investigation of $\mathrm{Cu}$-oxide nanorods formation, it is possible to prepare them even at lower temperatures. Therefore, the catalytic role of the surfactants can not be ignored in addition to template.

Conclusion

In conclusion, a simple method for synthesizing nanorods using various surfactants has been successfully developed. Although the nanorod formation of copper oxide in the presence of polyethylene glycol exothermic peaks for as-synthesized nanorods in the presence of SDS, CTAB and Triton X-100 below and above CMCs are shown in Table 1. It can be seen that the thermal stability of nanorods prepared above $\mathrm{CMC}$ is more when compared to that synthesized below CMC.

The binding energies of the metals in the assynthesized samples were probed by XPS. The wide scan XPS spectra of the as-synthesized samples in the presence of different surfactant micelles are shown in Fig. 4. It can be seen that no other peaks except those corresponding to $\mathrm{C}, \mathrm{Cu}$ and $\mathrm{O}$ are present in the spectra indicating the purity of the samples. The high resolution XPS spectra of the copper oxide nanorods in the presence of SDS, CTAB and Triton X-100 micellar concentrations are shown in Fig. 5. The $\mathrm{Cu}_{2 p}$ peak lies at 933.38, 933.64 and $933.55 \mathrm{eV}$ for nanorods in the presence of SDS, CTAB and Triton X-100, respectively with a satellite feature located at a higher binding energy by about $8.5 \mathrm{eV}$. These results are in agreement with those cited in the literature (Wang et al., 2002). In order to find the effect of concentration of surfactant on the binding energies, XPS analysis for nanorods prepared in the presence of surfactants below CMC was also carried out. The graphical representations of XPS measurements carried out for samples prepared below CMCs are not shown here to save journal space. However, the data are presented in Table 2. It can be seen that for SDS and CTAB based CuO
Fig. 5. High resolution XPS spectra taken for $\mathrm{Cu}_{2 p}$ of the as-prepared $\mathrm{CuO}$ nanorod samples using (a) SDS, (b) CTAB and (c) Triton $X-100$ micelles.
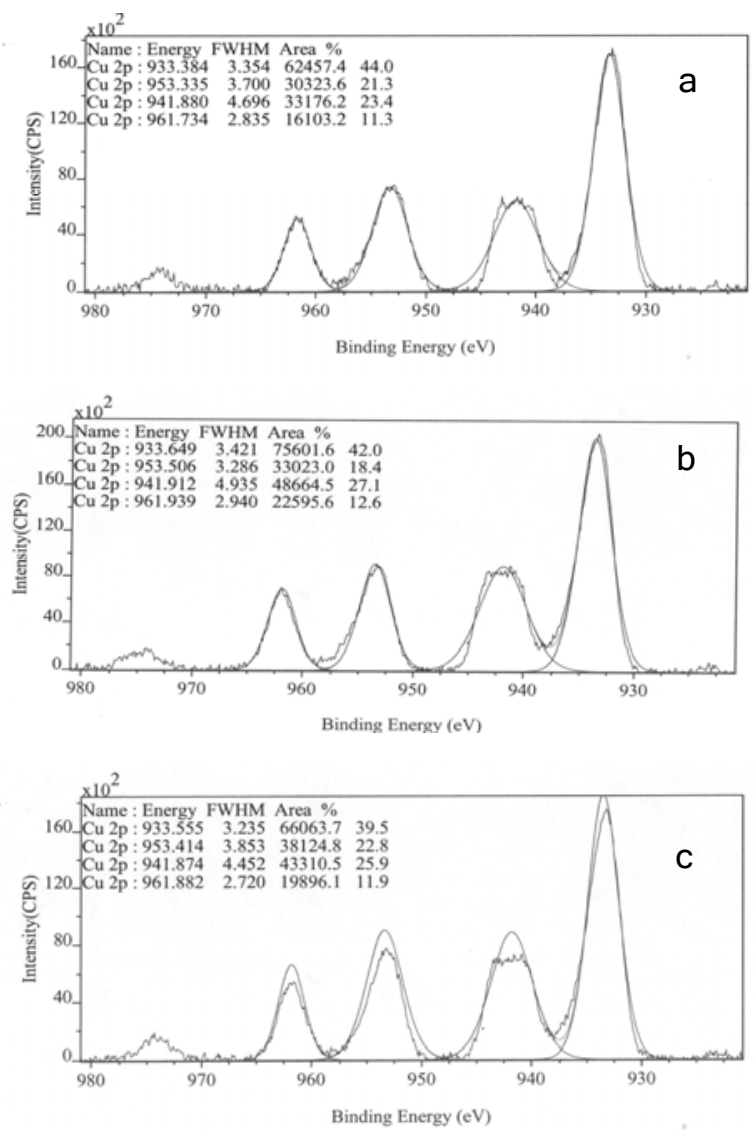
has been reported in the recent past, the above nanorod formation in presence of SDS surfactant micelles in our present investigation is superior to the reported one. The advantage of this process is that it is fast, simple and efficient with potential varied applications. The role of charge and concentrations of the surfactants in the preparation of the nanorods has been proved. It has been found that the formation of the $\mathrm{Cu}$-oxide nanorods in the presence of anionic SDS micelles is better with higher thermal stability and possessing lower binding energy with regard to $\mathrm{Cu}_{2 p}$ peak. This is due to the interaction between oppositely charged ions viz. anionic SDS micelles and cationic $\mathrm{Cu}$ metal. However, in CTAB micelles, repulsions are normally observed. The principles used in this work are simple and can be easily adapted to other metal oxide systems.

\section{Acknowledgements}

Financial assistances received from the Council of Scientific and Industrial Research, India and the Department of Science and Technology, India are gratefully acknowledged. The XRD and XPS experiments were carried out at Indian Institute of Technology, Madras and Indian Institute of Chemical Technology, Hyderabad, respectively.

\section{References}

1. Bakshi MS, Kaur AKG, Torigoe $K$ and Esumi $K$ (2006) Effect of Sodium dodecylsulfate and Dodecyltrimethyl Ammonium Bromide on the Morphologies of Gold Nanoparticles in the Presence of Poly (amidoamine) Dendrimers. $J$. Nanosci. Nanotechnol. 6, 644-650.

2. Barres RM (1982) Hydrothermal Stability of Zeolites, Academic Press, London.

3. Berry AD, Gaskill KD, Holm RT, Cukaukas EJ, Kaplan R and Henry RL (1988) Formation of high $T_{c}$ superconducting films by organometallic chemical vapor deposition. Appl. Phys. Lett. 52, 1743-1748.

4. Burch R, Cruise NA, Gleeson D and Tsang SC (1996) Surface-grafted manganese-oxo species on the walls of MCM-41 channels-a novel oxidation catalyst. Chem. Commun. 951952.

5. Duan XF, Huang $Y$, Agarwal $R$ and Lieber CM (2003) Single-nanowire electrically driven laser. Nature. 421, 241-244.

6. Guillemin G, Patat JL, Fournie S and Chetail M (1987) The use of coral as a bone graft substitute. J. Biomed. Mater. Res. 21, 557-567.

7. Hao E, Li S, Bailey RC, Zou S, Schatz GC and Hupp JT (2004) Optical Properties of Metal Nanoshells. J. Phys. Chem. B. 108, 12241229.
8. Hwang YK, Lee K-C and Kwon Y-Uk (2001) Nanoparticle routes to mesoporous titania thin films. Chem. Commun. 1738-1739.

9. James J, Ramalechume $C$ and Mandal $A B$ (2005) Self-diffusion studies on PEO-PPOPEO triblock copolymer micelles in SDS micelles and vice versa using cyclic voltammetry. Chem. Phys. Lett. 405, 84-89.

10. Jiang $Y$, Wu Y, Zhang SY, Xu CY, Yu WC, Xie Y and Qian YT (2000) A Catalytic-Assembly Solvothermal Route to Multiwall Carbon Nanotubes at a Moderate Temperature. J. Am. Chem. Soc. 122, 12383-12384.

11. Joint committee on Powder Diffraction Standards (1991) Diffraction Data File, No. 5661, JCPDS International center for Diffraction Data, Pennsylvania.

12. Liao X-H, Zhu J-M, Zhu J-J, Xu J-Z and Chen $\mathrm{H}-\mathrm{Y}$ (2001) Preparation of monodispersed nanocrystalline $\mathrm{CeO} 2$ powders by microwave irradiation. Chem. Commun. 937-938.

13. Lin H-P and Mou CY (1996) Tubules-Within-aTubule: Hierarchical Order of Mesoporous Molecular Sieves in MCM-41. Science. 273, 765-768.

14. Malandrino G, Condorlli GG, Lanza G, Fragala IL, Uccio SU and Valentino M (1997a) Growth of epitaxial $\mathrm{TIBaCaCuO}$ a-axis oriented films on $\mathrm{LaAlO} 3$ buffer layers grown on $\mathrm{SrTiO}$ (100) substrates. J. Alloys Compd. 251, 314317.

15. Malandrino G, Condorlli GG, Lanza G, Fragala IL, Uccio SU and Valentino M (1997b) Effect of $\mathrm{Ba}--\mathrm{Ca}$---Cu precursor matrix on the formation and properties of superconducting TI2Ba2Can-1CunOx films A combined metalorganic chemical vapour deposition and thallium vapour diffusion approach. J. Alloys Compd. 251, 332-336.

16. Mandal AB (1993) Self-diffusion studies on various micelles using ferrocene as electrochemical probe. Langmuir 9, 19321934.

17. Mandal AB and Nair BU (1991) Cyclic voltammetric technique for the determination of the critical micelle concentration of surfactants, self-diffusion coefficient of micelles, and partition coefficient of an electrochemical probe. J. Phys. Chem. 95, 9008-9013.

18. Mandal AB, Ray S and Moulik SP (1980) Mutual interactions of non-ionic and ionic detergents composed of triton X 100, SDS and CTAB. Indian J. Chem. 19A, 620-625.

19. Mandal AB, Ray S, Biswas AM and Moulik SP (1980) Physicochemical studies on the characterization of Triton X 100 micelles in an 
aqueous environment and in the presence of additives. J. Phys. Chem. 84, 856-859.

20. Moore VC, Strano MS, Haroz EH, Hauge RH, Smalley RE, Schmidt J and Talmon Y (2003) Individually Suspended Single-Walled Carbon Nanotubes in Various Surfactants. Nano Lett. 3, 1379-1382.

21. Ohgushi $H$, Okumura $M$ and Yoshikawa $T$ (1992) Bone formation processin porous calcium carbonate and hydroxyapatite. $J$. Biomed. Mater. Res. 26, 885-895.

22. Poizot $P$, Laruell $S$, Grugeon $S$, Dupont $L$ and Taracon JM (2000) Nano-sized transition-metal oxides as negative-electrode materials for lithium-ion batteries. Nature 407, 496-498.

23. Rakhshani AE (1986) Preparation, characteristics and photovoltaic properties of cuprous oxide-a review. Solid-State Electron. 29, 7-17.

24. Sun, J-H, Gong YJ, Fan W-H, Wu D and Sun Y-H (2000) Textural characterization of SiO2PEG xerogels. Chem. J. Chin. Univ. 21, 95-98.
25. Tanev PT, Chibwe M and Pinnavaia TJ (1994) Titanium-containing mesoporous molecular sieves for catalytic oxidation of aromatic compounds. Nature. 368, 321-322.

26. Wang H, Xu JZ, Zhu JJ and Chen HY (2002) Preparation of $\mathrm{CuO}$ nanoparticles by microwave irradiation. J. Crys. Growth 244, 8894.

27. Wang W, Zhan Y and Wang G (2001) Onestep, solid-state reaction to the synthesis of copper oxide nanorods in the presence of a suitable surfactant. Chem. Commun. 727-728.

28. Wu MK, Ashburn JR, Torng CJ, Hor PH, Meng RL, Gao L, Huang ZJ, Wang YQ and Chu CW (1987) Superconductivity at $93 \mathrm{~K}$ in a new mixed-phase $\mathrm{Y}-\mathrm{Ba}-\mathrm{Cu}-\mathrm{O}$ compound system at ambient pressure. Phys. Rev. Lett. 58, 908910.

29. Zhu HW, Xu CL, Wu DH, Wei BQ, Vajtai R and Ajayan PM (2002) Direct Synthesis of Long Single-Walled Carbon Nanotube Strands. Science. 296, 884-886. 